\title{
PRÁTICAS DE SUSTENTABILIDADE EMPRESARIAL NO APL CALÇADISTA DE CAMPINA GRANDE - PB: UM ESTUDO DE CASO
}

\section{SUSTAINABILITY BUSINESS PRACTICE IN FOOTWEAR APL FROM CAMPINA GRANDE - PB: A CASE STUDY}

\author{
Raquel Andrade Barros ${ }^{1}$; Elisabeth de Oliveira Andrade ${ }^{2}$; Ana Cecília Feitosa de Vasconcelos ${ }^{3}$, \\ Gesinaldo Ataíde Cândido ${ }^{4}$ \\ ${ }^{1}$ Universidade Federal da Paraíba- UFPB - João Pessoa - Brasil \\ barrosrab@gmail.com \\ ${ }^{2}$ Universidade Federal da Paraíba- UFPB - João Pessoa - Brasil \\ bethoandrade@,gmail.com \\ ${ }^{3}$ Universidade Federal da Paraíba- UFPB - João Pessoa - Brasil \\ acvasconcelos@gmail.com \\ ${ }^{4}$ Universidade Federal de Campina Grande - UFCG - Campina Grande - Brasil \\ gacandido@uol.com.br
}

\begin{abstract}
Resumo
$O$ artigo tem como objetivo descrever a aplicação de práticas de sustentabilidade empresarial do APL Calçadista de Campina Grande - PB. Para tanto, utilizou-se como base o modelo proposto por Coral (2002), o qual compreende de três dimensões da sustentabilidade: econômica, social e ambiental. Em termos metodológicos a pesquisa caracteriza-se como sendo descritiva e conduzida sob a forma de estudo de caso. No que diz respeito às técnicas, utilizou-se a pesquisa bibliográfica, análise documental e observação não participante. Os resultados do estudo apontam que há a necessidade das empresas que compõem os APLs atuarem de modo conjunto e integrado, como forma de fortalecerem-se no atual ambiente organizacional globalizado, incorporando princípios que ultrapassem o limite da esfera econômica, voltando-se para aspectos sociais e ambientais, de modo a garantir a sustentabilidade corporativa.
\end{abstract}

Palavras-chave: arranjo produtivo local; sustentabilidade social; sustentabilidade econômica; sustentabilidade ambiental.

\section{Introdução}

Nas últimas décadas do século $\mathrm{XX}$, as transformações sócio-econômicas, políticas, ambientais e culturais ocorridas no cenário mundial e, por conseguinte, no contexto empresarial impulsionaram a discussão acerca de caminhos mais promissores para se alcançar uma atuação efetiva e, sobretudo, competitiva frente ao mercado. 
As exigências requeridas no atual cenário de competição elevada têm corroborado para uma redefinição nas formas de gestão das empresas, sobretudo, as de pequeno e médio porte, adequando-se aos novos contextos organizacionais, a fim de melhor competirem com os seus concorrentes. Neste sentido, emerge o conceito de Arranjos Produtivos Locais (APLs), que segundo a Redesist são aglomerações territoriais de agentes econômicos, políticos e sociais com foco em um conjunto específico de atividades econômicas que apresentam vínculos mesmo que incipientes.

Em função da maior complexidade das atividades desempenhadas pelas empresas, que são necessárias para a sobrevivência no mercado, verifica-se cada vez mais a necessidade do trabalho realizado de forma associada ou cooperativa com outras empresas. Isto tem contribuído para a diminuição dos riscos e o aumento de sinergia entre as empresas, especialmente no que diz respeito às pequenas empresas (CASSAROTO FILHO; PIRES, 1999).

As antigas estruturas organizacionais baseadas no tradicionalismo, individualismo e práticas burocráticas vêm cedendo espaço para comportamentos mais flexíveis e participativos, como forma de aprimorar as competências das empresas, viabilizando assim, o percurso para torná-las aptas ao alcance de um desenvolvimento consolidado.

Diante deste panorama, as empresas passam a se reestruturar para se adequarem a esta nova percepção. As pressões sociais e restrições impostas fazem com que as empresas sejam forçadas a buscar formas de reduzir seu impacto ambiental e a melhorar sua imagem frente a sua responsabilidade social. Neste sentido, muito tem sido feito para a sustentabilidade do setor produtivo (CORAL, 2002).

Para Buarque (1999), o alcance da sustentabilidade requer um processo de mudança social e elevação das oportunidades da sociedade, compatibilizando, no tempo e no espaço, o crescimento e a eficiência econômica, a conservação ambiental, a qualidade de vida e a eqüidade social, partindo de um claro compromisso com o futuro e a solidariedade entre gerações.

Diante de tais considerações, verifica-se que os APLs têm os seus desempenhos econômicos baseados em sua forma de organização industrial, na existência de instituições e de relações sociais, sendo o seu desenvolvimento pautado em um processo de transformação mais complexo, uma vez que tem uma parcela significativa no alcance do desenvolvimento local sustentável, apresentando um papel que vai além da perspectiva econômica, ampliando-se ao social e ambiental.

$\mathrm{Na}$ indústria de calçados, mas precisamente no APL Calçadista de Campina Grande - PB, pode-se perceber um crescimento considerável ao longo dos anos, obtendo uma elevada participação na economia do município, o que remete para a necessidade em se realizar estudos voltados para análise da existência de práticas sociais e ambientais, além da econômica. Observa-se que as indústrias calçadistas instaladas são em sua maioria de pequeno porte, o que desperta uma 
preocupação em relação aos impactos que causam ao meio ambiente, na medida em que apresentam produção considerável e, paralelamente, ainda não possuem sistemas de gestão ambiental.

Neste contexto, este artigo tem como objetivo descrever a aplicação de práticas de sustentabilidade empresarial do APL Calçadista de Campina Grande - PB. Para tanto, utilizou-se como base o modelo proposto por Coral (2002), o qual compreende de três dimensões da sustentabilidade: econômica, social e ambiental.

Além desta parte introdutória, o artigo encontra-se assim estruturado: arcabouço teórico explicitando os seguintes temas - arranjos produtivos locais; um enfoque sobre a Sustentabilidade Empresarial; e Sustentabilidade: Social, Econômica e Ambiental. Em seguida estão explicitados os procedimentos metodológicos e a caracterização do APL em estudo, além da análise da sustentabilidade empresarial. Posteriormente, são realizadas as considerações finais, onde foi estabelecida relação entre os resultados obtidos e os objetivos propostos inicialmente.

\section{Fundamentação teórica}

\subsection{Arranjos produtivos locais - APLs}

As constantes oscilações econômicas e sociais presenciadas no ambiente organizacional têm feito emergir a necessidade de criação e/ou fortalecimento das relações interempresariais, de modo que haja uma maior facilidade de circulação de informações, desenvolvimento de ações cooperativas e, sobretudo, estabelecimento de parcerias entre os atores sociais e institucionais.

As mudanças nas formas de gestão das empresas apresentam como principal objetivo enquadrá-las neste novo cenário em que para sobreviverem e serem competitivas necessitam ultrapassar os limites econômicos, exercendo, sobretudo, um papel social frente a sociedade.

Nesse sentido, verifica-se a importância em se debater a temática de arranjos produtivos locais (APLs), uma vez que se caracterizam como uma aglomeração de agentes econômicos, políticos e sociais, que estão inseridos numa mesma localidade territorial e, além disso, articulam-se e interagem de forma cooperativa (CASSIOLATO; SZAPIRO, 2002).

Para que sejam caracterizadas como APLs, dentro do que define a literatura, as concentrações geográficas de empresas devem atender alguns requisitos básicos, os quais se referem à quantidade de empresas pequenas e médias concentradas, índices de especialização da produção de determinados bens, existência de relacionamentos formais e informais, compartilhamento de cultura, níveis de cooperação e competição, entre outros (SEBRAE, 2004; PUGA, 2003).

De acordo com o Banco Nacional de Desenvolvimento Econômico e Social - BNDES (2004), o arranjo produtivo local é conceituado como uma concentração geográfica de empresas, 
sobretudo pequenas e médias, e outras instituições que se relacionam em um setor ou cadeia produtiva particular, tendo sua existência definida a partir de vantagens competitivas locacionais.

Entre as inúmeras vantagens oriundas da aglomeração de empresas e da incorporação de comportamentos cooperativos pode-se destacar a redução de custos, a disseminação de informação e conhecimento, e principalmente, a maior agilidade para solucionar problemas que isoladamente iriam demandar maior tempo.

Para Carvalho et al (apud Boisier, 2001), a consolidação dos arranjos produtivos locais torna-se especialmente importante em regiões pouco desenvolvidas e com baixo nível de emprego e renda, por isso são objeto de inúmeras políticas de desenvolvimento econômico regional e de políticas industriais.

De acordo com Ruthes e Nascimento (2006), é preciso ter em mente que a sustentabilidade local precisa estar alinhada com a vocação, especialidade e potencialidades da região. Este alinhamento é importante para que as organizações possam formular estratégias que realmente contribuam com o desenvolvimento local.

Paralelamente a importância dos arranjos no processo de desenvolvimento de uma dada região, a construção de um ambiente de cooperação necessita de um fator determinante, que é uma cultura social bastante aprimorada. Ainda que o território possua grandes potencialidades em termos de recursos naturais, o principal agente requerido para o desenvolvimento é a população. Isto porque por meio da população acontecem as diversas ligações entre o território e o ambiente externo (CASAROTTO FILHO; PIRES, 1999).

Neste sentido, vincular os APLs ao processo de desenvolvimento local e sustentável em parceria com a atuação da comunidade torna-se uma vertente importante, uma vez que tal aglomeração poderá contribuir direta e/ou indiretamente nas atividades econômicas, sociais e ambientais que possam estar sendo desenvolvidas e implementadas.

Sendo assim, acredita-se que as empresas sustentáveis são as que conseguem promover, de forma equilibrada e harmônica, crescimento econômico e qualidade de vida, sem dissociarem-se das responsabilidades com o meio ambiente e com a sociedade.

\subsection{Um enfoca sobre a sustentabilidade empresarial}

O termo sustentabilidade diz respeito à utilização de recursos para atender às necessidades do presente sem comprometer a capacidade das gerações futuras em atender as suas próprias necessidades (desenvolvido por Gro Brundtland em 1990 e aprovado na Conferência das Nações Unidas para o Meio Ambiente e o Desenvolvimento - Rio 92). 
A sustentabilidade do processo de desenvolvimento local depende, basicamente, da adesão social, sua manutenção e internalização do conceito de sustentabilidade. A mudança para o novo paradigma de produção flexível requer mudanças de atitude e comportamento dos indivíduos, no intuito de absorver o mesmo. (CASAROTTO FILHO; PIRES, 1999).

$\mathrm{Na}$ área empresarial, a preocupação com a sustentabilidade tem se generalizado e um grupo mais envolvido com esta inquietação criou uma entidade voltada a sustentabilidade empresarial, ligada ao movimento internacional de empresários com este foco (ALTENFELDER, 2004).

De acordo com Almeida (2002), uma empresa para ser sustentável deve buscar em todas as suas ações e decisões a eco eficiência, procurando produzir mais e com melhor qualidade gerando menos poluição e utilizando menos recursos naturais. A empresa que é partidária dos princípios da sustentabilidade deve ainda ser socialmente responsável, assumindo que está imersa num ambiente social em que influi ao mesmo tempo em que sofre influência. A motivação dos líderes empresariais deve ser respaldada numa visão de longo prazo, em que se leve em consideração os custos futuros e não somente os custos presentes.

A incorporação da sustentabilidade no universo empresarial vai estar condicionada a vários aspectos como as crenças do próprio dirigente da empresa, a mobilização da sociedade, a influência do mercado nacional e internacional, a atuação do setor público, a pressão de organismos internacionais, entre inúmeros outros fatores de ordem conjuntural.

A contribuição para o desenvolvimento sustentável por parte das empresas, conforme afirma Coral (2002) acontece quando há modificações nos sistemas produtivos adotados pelas empresas, tornando-os mais eficientes e com impactos não negativos no meio ambiente. Além disso, as empresas devem assumir o papel de recuperar as áreas degradadas e oferecer produtos e serviços que promovam a melhoria do desempenho ambiental dos consumidores.

Assim, surge a vertente que liga não mais as políticas públicas ao desenvolvimento sustentável, mas direciona o setor privado à ações que impliquem em maior sustentabilidade. Entretanto, para Young e Steffen (2006), ainda que haja um elevado número de empresas que direcionem seus esforços para a sustentabilidade, a ação pública não deverá ser substituída, mas agir em conjunto.

$\mathrm{Na}$ verdade, o grande diferencial do conceito de sustentabilidade no meio empresarial é associar a questão da ecoeficiência com a noção de responsabilidade social corporativa. A empresa considerada sustentável é aquela que procura considerar em suas ações as dimensões econômica, social e ambiental. Em outras palavras, a empresa continua visando o lucro, seu objetivo primordial, só que passa a considerar o impacto de suas atividades no meio ambiente procurando amenizá-las de maneira eficiente, desempenhando ao mesmo tempo ações de cunho social, seja em benefício de seus funcionários ou da comunidade. 
Dessa forma, o tripé da sustentabilidade ou Triple-Bottom-Line passa a ser reconhecido entre os pesquisadores e torna-se uma ferramenta fundamental para que as empresas desenvolvam ações que permeiem as três dimensões: econômica, social e ambiental.

\subsubsection{Sustentabilidade: social, econômica e ambiental}

O desenvolvimento sustentável apresenta três grandes dimensões principais: crescimento econômico, eqüidade social e equilíbrio ecológico, em outras palavras o desenvolvimento sustentável equilibra as dimensões econômica, social e ambiental (CARVALHO; VIANA, 1998).

O estabelecimento de uma civilização na qual ocorra uma distribuição mais eqüitativa das riquezas é o principal objetivo da sustentabilidade social. Uma melhor alocação dos recursos e uma melhor gestão possibilitariam a sustentabilidade econômica. O equilíbrio social é visto como medida da eficiência econômica, e não a lucratividade empresarial.

$\mathrm{O}$ conceito de sustentabilidade tornou-se amplamente conhecido entre as empresas e os pesquisadores, sendo útil para interpretar as interações extra-empresariais e especialmente para ilustrar a importância de uma visão da sustentabilidade mais ampla, além de uma mera sustentabilidade econômica. Para Coral (2002), este conceito integra as três bases para a sustentabilidade empresarial, a saber: econômica, ambiental e social.

Figura 1- Bases para sustentabilidade empresarial

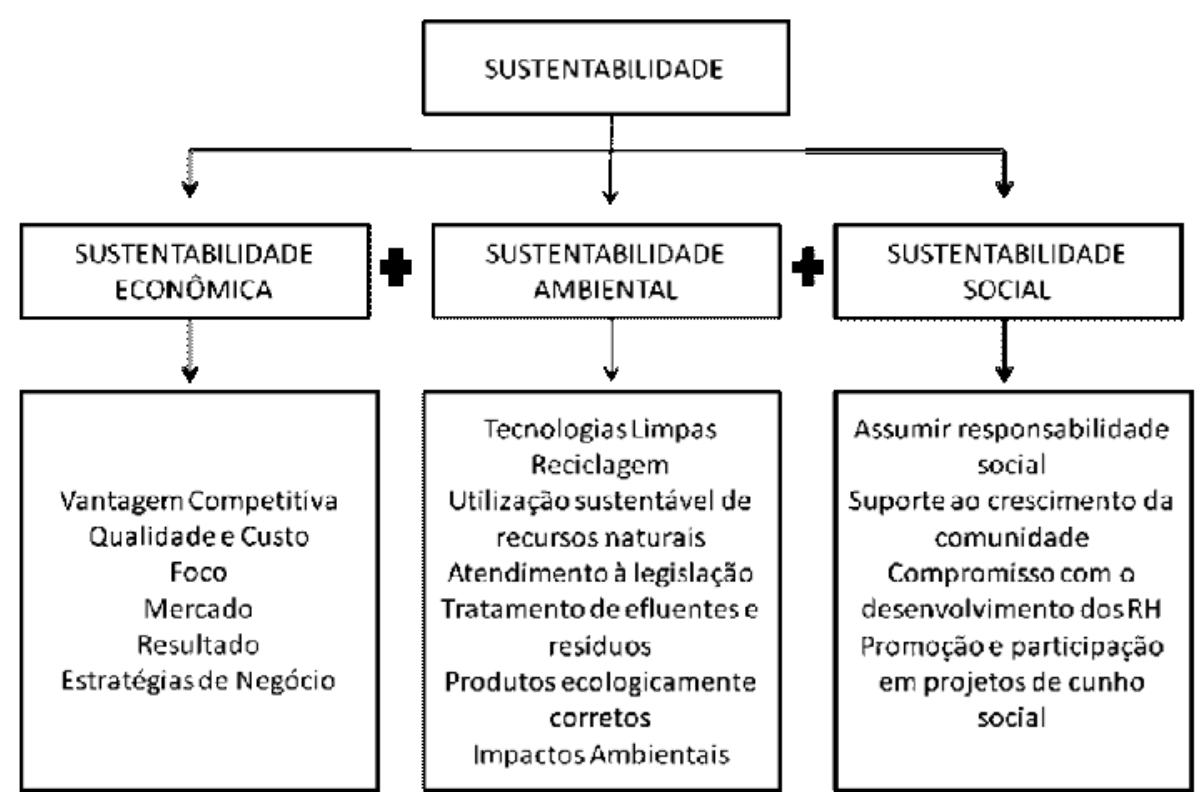

Fonte: Coral (2002)

Cada seção que compõe o modelo de sustentabilidade empresarial proposto por Coral (2002) é caracterizada por um conjunto de variáveis pertinentes à temática, onde a intensificação de cada uma dessas variáveis elencadas acima tende a ser analisada positivamente na perspectiva da 
sustentabilidade empresarial. Em seguida, para melhor entendimento, segue especificadamente as seções que compõem cada processo do modelo referenciado.

\section{- Sustentabilidade econômica}

A demanda dos países por políticas que visassem o desenvolvimento sustentável tornou-se o grito de muitos ao longo das duas últimas décadas. $\mathrm{O}$ fato do processo de regeneração do meio ambiente não acompanhar o padrão de consumo atual têm levado as nações a assinarem acordos que visam um desenvolvimento com mais equidade e menos degradação.

Em dias não muito anteriores a este, a economia mundial elevou-se em escala bastante superior no sentido de extrair cada vez mais recursos naturais e eliminar mais rejeitos contribuindo para maiores índices de poluição, elevando também a preocupação com esse fenômeno. A referida escala da economia possui dois componentes básicos, o primeiro é a dimensão da população humana e o segundo o nível médio de renda per capita.

A relação desses dois componentes com a questão ambiental é forte, uma vez que não importando o quão pobre seja determinada população, se sua taxa de crescimento populacional é elevada, mais alimentos, bens e serviços são requeridos. Dessa forma, tem-se o aumento de emissões e resíduos, implicando no aumento da escala econômica e impactos no meio ambiente (MUELLER, 2007).

Conforme Cavalcanti (2001), o posicionamento em relação ao meio ambiente ilustra o processo fundamental de acúmulo de riqueza dos modelos econômicos convencionais que não considera a dimensão ecológica como unidade pertencente ao sistema econômico e pressupõe um crescimento econômico ilimitado. Sendo assim, há uma necessidade de se avaliar a eficiência econômica no âmbito macrossocial, não enfatizando apenas a lucratividade empresarial (ALMEIDA, 1999).

Dessa forma, o modelo de sustentabilidade apresentado tem como uma das suas dimensões a sustentabilidade econômica, sendo as variáveis que a compõem:

- Vantagem competitiva;

- Qualidade e custo;

- Foco;

- Mercado;

- Resultado;

- Estratégias de negócios. 
O maior ou menor desempenho financeiro das empresas é que vai determinar o aporte financeiro das empresas destinado a ações que visem a sustentabilidade. Sendo assim, o bom funcionamento do tripé está aliado a bons resultado econômicos que por sua vez retornarão à sustentabilidade, formando um ciclo.

\section{- Sustentabilidade ambiental}

Dada a representatividade econômica e social que uma organização detém no ambiente em que se encontra inserida, bem como o poder de influência junto aos consumidores e a sociedade em geral, torna-se prudente e necessário que as empresas inseridas no atual contexto ampliem o mero papel de fornecedora de produtos, atuando de modo mais abrangente ao contribuir com as questões de ordem ambiental em sua gestão.

Conforme ressalta Maximiano (2000), as organizações são instituições sociais que existem com a autorização da sociedade, utilizam seus recursos e afetam sua qualidade de vida, o que remete para a necessidade em exercer um papel responsável socialmente. Neste sentido, identificase uma nova postura das organizações, voltada para uma preocupação com fatores que afetam as gerações futuras, mantendo, sobretudo, o seu objetivo primordial que é a obtenção do lucro.

Concomitantemente, é vinculado o termo eco eficiência, o qual é conceituado como uma nova filosofia de gestão empresarial que incorpora a gestão ambiental, associando-a aos objetivos econômicos, cujo principal objetivo é fazer a economia crescer qualitativamente, e não quantitativamente, o que compreende ações do tipo: redução do gasto de materiais com bens e serviços; redução do gasto de energia com bens e serviços; redução da emissão de substâncias tóxicas; intensificação da reciclagem de materiais; maximização do uso sustentável de recursos renováveis; prolongamento da durabilidade dos produtos; e agregação de valor aos bens e serviços (ALMEIDA, 2005).

Sendo assim, a sustentabilidade ambiental é uma das esferas que compõem a temática do desenvolvimento sustentável, em conjunto com as esferas sociais, econômicas, institucionais e políticas, referindo-se ao uso consciente dos recursos naturais e a minimização da degradação ambiental, nas etapas que vão desde a aquisição de matéria-prima até a entrega do produto final ao cliente.

A discussão da sustentabilidade ambiental é oriunda da limitação e má uso dos recursos disponíveis, podendo ser revertida pela utilização de tecnologias limpas e, sobretudo, pela criação e consolidação de mecanismos administrativos de proteção ambiental. 
Segundo Maimon (1996), define-se a gestão ambiental como sendo um conjunto de procedimentos que tem a função de gerir ou administrar uma organização, de forma a obter o melhor relacionamento com o meio ambiente.

Quanto às variáveis que compõem a sustentabilidade ambiental e que serão tomadas como base neste estudo, tem-se:

- Tecnologias limpas;

- Reciclagem;

- Utilização sustentável de recursos naturais;

- Atendimento à legislação;

- Tratamento de efluentes e resíduos;

- Produtos ecologicamente corretos; e

- Impactos ambientais.

Como se pode verificar caracterizam-se por ser variáveis de grande importância quando se almeja analisar o comportamento das empresas, na medida em que permite constatar a presença e/ou ausência dessas práticas ambientais internamente. Na verdade, ainda prevalece nas ações empresariais uma postura baseada no imediatismo, onde o gerenciamento de práticas ambientais só ocorre quando há uma imposição das leis e regulamentações criadas no país, daí a importância em se adentrar nestes aspectos.

\section{- Sustentabilidade social}

Nos últimos tempos, o envolvimento do setor privado com os problemas sociais vem deixando de ser uma opção de filantropia e passa a se caracterizar como um mecanismo de atuação estratégica. Os autores Mello Neto e Froes (1999) defendem a importância da atuação social das empresas com caráter estratégico, que quando assumida de forma consistente e inteligente pela empresa, pode contribuir de forma decisiva para a sustentabilidade, bem como para o desempenho empresarial, uma vez que passa a imagem de uma organização de consciência social comprometida com a busca de soluções para graves problemas sociais que assolam a comunidade.

Para Smith (1994) esta questão pode ser abordada associando a ação social diretamente à estratégia de negócio, uma vez que as empresas competem entre si em preço e em cidadania.

Esta visão integrada por parte das organizações está implícita nas escolhas organizacionais, dado que colocar o desenvolvimento social e a qualidade de vida como finalidades mais amplas tem repercussões profundas na e para a sociedade (DOWBOR, 2001). Tal visão corrobora para a 
existência de um novo paradigma social que torna possível que mecanismos e processos decisórios de sucesso empresarial, tais como a orientação para resultados e a ênfase na inovação, passem a ser transportados pelas empresas para o setor social, juntamente com investimentos crescentes de recursos financeiros e humanos.

Vale compreender a distinção da função social da empresa com a sua responsabilidade com a comunidade. De acordo com Fischer (2003) as funções sociais da empresa são inerentes às suas funções negociais, tais como geração de empregos, remuneração do capital e obediência à legislação, e estas são apenas uma parte de sua responsabilidade social, sendo complementada por ações voltadas ao desenvolvimento humano.

Assim, pode-se compreender que a responsabilidade social envolve uma série de posturas éticas adotadas pelas empresas, as quais incluem a relação com seus consumidores, fornecedores, funcionários, bem como a comunidade a qual estão inseridas.

Nesse sentido, a sustentabilidade social vai além do compromisso das organizações com seus funcionários e stakerolders, e passa a avaliar as ações da mesma, a partir do seu comprometimento com a comunidade do seu entorno.

No caso específico desse estudo, o qual tomará como base o modelo de sustentabilidade empresarial proposto por Coral (2002), explicitado na Figura 01, serão utilizadas para análise as variáveis que compõem a sustentabilidade social, a saber:

- Assumir responsabilidade social;

- Suporte ao crescimento da comunidade;

- Compromisso com o desenvolvimento de RH;

- Promoção e participação em projetos de cunho social.

Inúmeros são os benefícios resultantes para as organizações que adotam práticas de cunho social em qualquer que seja a sua esfera de atuação. Dentre os benefícios que agregam valor para as organizações pode-se destacar: ganhos de imagem corporativa; maior apoio, motivação e confiança dos funcionários e parceiros; melhor relacionamento com o governo; dentre outros.

A partir da explicitação da teoria que justifica a importância desse estudo, bem como do modelo que será tomado como base para análise da sustentabilidade empresarial do APL calçadista da cidade de Campina Grande (PB), a sua consolidação pode ser entendida a partir dos procedimentos metodológicos que se segue. 


\section{Procedimentos metodológicos}

A pesquisa realizada pode ser caracterizada como descritiva e conduzida sob a forma de estudo de caso, a qual procurou descrever a aplicação de práticas de sustentabilidade empresarial do APL Calçadista de Campina Grande - PB, observadas pela perspectiva econômica, social e ambiental.

A análise dos dados foi embasada na inferência obtida a partir da triangulação dos dados existentes, a qual se refere à correlação entre diferentes fontes de dados (referencias bibliográficas, documentos e observação não participante). Buscaram-se, na base de dados utilizada informações acerca das variáveis que compõem o modelo de sustentabilidade utilizado, a qual compreende: sustentabilidade econômica, sustentabilidade ambiental e sustentabilidade social.

Como fonte de dados secundários, esta pesquisa obteve informações do Relatório Promos, intitulado: Arranjos Produtivos de Couros e Calçados de Campina Grande/PB (ARAGÃO, 2006), da nota técnica referente ao Arranjo Produtivo Coureiro-Calçadista de Campina Grande/PB (LEMOS; PALHANO, 2000), e documento técnico científico referente a Análise dos Impactos Socioambientais das Micro e Pequenas Indústrias de Calçados Instaladas na Cidade de Campina Grande (FRANÇA; LEITE; PRASAD, 2007).

Diante de tais considerações acerca do percurso metodológico utilizado para realização deste artigo, serão enfatizados no tópico seguinte os resultados obtidos quanto à análise do setor de calçados no município de Campina Grande - PB.

\section{Apresentação e análise dos resultados}

\subsection{Caracterização do arranjo produtivo local - APL}

A atividade coureira no município de Campina Grande teve início da década de 20, mas precisamente no ano de 1923 com a criação de Curtumes na cidade. De acordo com Furlanetto et al (2007), até então a produção destinava-se inicialmente à confecção de selas, arreios e artigos para montarias, onde eram bastante utilizadas no meio rural. $\mathrm{O}$ desenvolvimento das atividades de produção de calçados, só começa a ocorrer com maior intensidade no final da década de 60 até meados da década de 80, por meio das políticas delineadas pela SUDENE (Superintendência de Desenvolvimento do Nordeste) com a concessão de incentivos fiscais.

Atualmente, o arranjo produtivo de calçados de Campina Grande é composto fundamentalmente por produtores de micro e pequeno porte de calçados e artefatos de couro ou de material sintético, sendo cerca de 40 empresas formalmente constituídas e um contingente de 
produtores informais em torno de 187 unidades. Tais empresas se caracterizam como sendo de estrutura familiar, característica encontrada, também, na maioria dos outros pólos calçadistas espalhados pelo Brasil.

As empresas caracterizadas pelo porte de microempresa possuem em média de 5 a 15 funcionários e têm uma capacidade de produção mensal que fica entre 300 e 500 dúzias de pares/mês, enquanto que as pequenas empresas que possuem em média 25 a 40 funcionários conseguem produzir entre 1.000 e 1.500 dúzias de pares/mês. Encontram-se no arranjo, ainda que de forma incipiente, um total de sete empresas fornecedoras de insumos e componentes para a produção de calçados, que totalizam 140 empregos diretos.

Outro fator que merece destaque é o número expressivo de instituições sediados no município de Campina Grande, que apesar de não serem diretamente responsável pela coordenação do APL Calçadista, estão envolvidas direta ou indiretamente em apoiá-lo. Dentre as instituições existentes no município, destaca-se a Federação das Indústrias da Paraíba (FIEP) e o sistema SENAI (que possui uma escola localizada no Centro de Tecnologia e Calçados Albano Franco (CTCC), sendo o único centro no Brasil especializado na área de couro e calçados), Sindicato da Indústria de Calçados da Paraíba, Universidade Federal de Campina Grande (que possui o curso de graduação em Engenharia de Produção com uma de suas áreas de atuação sendo couro e calçados), SEBRAE e Banco do Nordeste.

\subsection{Aplicação do modelo}

\subsubsection{Sustentabilidade econômica}

O mercado de atuação das empresas do APL de calçados de Campina Grande concentra-se na região Nordeste. Assim, a localização dos concorrentes pode ser observada conforme Tabela 1:

Tabela 1 - Localização dos competidores

\begin{tabular}{|l|c|c|}
\hline \multicolumn{1}{c}{ Localização } & Freqüência & $\%$ \\
\hline Campina Grande & 9 & 19,6 \\
Estado (Paraíba) & 12 & 26,1 \\
Nordeste & $\mathbf{1 4}$ & $\mathbf{3 0 , 4}$ \\
Em outras regiões do país & 11 & 23,9 \\
Total & $\mathbf{4 6}$ & $\mathbf{1 0 0 , 0}$ \\
\hline
\end{tabular}

Fonte: Aragão (2006, p.46)

No que se refere à estratégia de negócio definida pelo arranjo produtivo de calçados verificou-se a presença de alguns elementos que influenciam decisivamente esse processo de escolha, a saber: 
Quadro 01-Estratégia de negócios do APL calçadista de Campina Grande - PB

\begin{tabular}{|c|c|}
\hline Elementos & Análise do APL em estudo \\
\hline Mercado interno & $\begin{array}{l}\text { As firmas estão voltadas para atingir os principais mercados potenciais } \\
\text { para os seus produtos, sendo a região Nordeste o principal mercado } \\
\text { alvo. }\end{array}$ \\
\hline Estreitamento dos mercados & $\begin{array}{l}\text { As firmas do arranjo consideram cada vez mais o acirramento da } \\
\text { concorrência como elemento que atua decisivamente em sua estratégia, } \\
\text { pressionando-as para melhorar a eficiência alocativa dos recursos e se } \\
\text { tornarem mais competitivas. }\end{array}$ \\
\hline Exigência dos consumidores & $\begin{array}{l}\text { Este é um fator que tem contribuído para pressionar as firmas na } \\
\text { melhoria da qualidade de seus produtos, que cresce de importância } \\
\text { conforme o nicho de mercado que a empresa está atuando. }\end{array}$ \\
\hline $\begin{array}{l}\text { Condições de acesso a novas } \\
\text { tecnologias }\end{array}$ & $\begin{array}{l}\text { As firmas, principalmente as de maior porte no arranjo, estão mais } \\
\text { orientadas para incorporar melhorias tecnológicas. }\end{array}$ \\
\hline
\end{tabular}

Fonte: Elaborado com base em Palhano (2000)

Pode-se perceber ainda, que a base da estratégia das empresas que compõem o referido APL é a redução dos preços através da diminuição dos custos de produção. Entretanto, elementos relacionados à melhoria da qualidade dos produtos, maior flexibilidade na produção, redução no cumprimento dos prazos de entrega e aumento do grau de sofisticação tecnológica são elementos que também interferem nas decisões estratégicas só que em uma menor intensidade quando comparado ao elemento custo.

Conforme Aragão (2006), a pressão exercida pelos consumidores faz com que, principalmente as empresas que fabricam calçados e artefatos de couro se empenhem em melhorar a qualidade dos seus produtos. Para tanto, nas empresas que fabricam produtos a partir de materiais sintéticos mais populares, a competitividade encontra-se baseada no preço.

$\mathrm{O}$ arranjo em análise adota o preço como o principal atributo do calçado local, visando alcançar nichos de mercados com baixo poder aquisitivo e, assim, obter uma elevada parcela de mercado. Vale ressaltar, que competir no mercado apenas pelo preço não permite uma agregação de valor expressiva, o que pode resultar na adoção maciça de políticas que incentivam baixos salários, altos índices de rotatividade de mão-de-obra e a precarização do trabalho.

Neste sentido, há um investimento em modernização, porém sem expansão da capacidade produtiva, priorizando a fabricação de produtos tecnologicamente similares ou da mesma área de comercialização. Conforme a Tabela 2, os custos da produção em geral apresentam a seguinte composição: 
Tabela 2 - Composição dos custos de produção

\begin{tabular}{cc}
\hline Fatores & $\mathbf{\%}$ \\
\hline Matéria-prima & 59,7 \\
Salários & 17,5 \\
Tempo de fabricação & 5,7 \\
Qualidade do produto & 6,5 \\
Preço dos concorrentes & 5,0 \\
Outros fatores & 5,5 \\
Total & $\mathbf{1 0 0 , 0}$ \\
\hline
\end{tabular}

Fonte: Aragão (2006, p. 47)

Como se pode visualizar acima, destaca-se um elevado percentual $(59,7 \%)$ dos custos que envolvem a produção no setor coureiro-calçadista vinculados à matéria-prima e, em segundo lugar, os salários com $17.5 \%$ dos custos.

Quanto à variável Vantagem Competitiva, as empresas elencaram a localização, qualidade, custo da mão-de-obra e, com menor intensidade, a proximidade ao centro tecnológico como sendo fatores geradores de vantagem.

Por último, o faturamento de US\$ 62,9 milhões de em 2007 possuía tendência de crescimento para os próximos anos devido às políticas de incentivo dadas ao setor, trazendo com isso uma efetiva participação no PIB municipal, o qual é representado em $16 \%$ pela produção industrial (ABICALÇADOS, 2009).

Com base na análise das variáveis que compõem a sustentabilidade econômica, verifica-se que o APL calçadista apresenta-se relativamente favorável, uma vez que a adoção pela estratégia competitiva custo restringe a um nicho de mercado com consumidores de baixo poder aquisitivo. Dessa forma, com o aumento da disseminação da informação, o consumidor tem modificado o perfil de consumo no que tange à qualidade, exigindo dessas empresas preços competitivos, todavia, com maior valor agregado.

\subsubsection{Sustentabilidade ambiental}

Para alcançar o desenvolvimento sustentável, torna-se necessário atingir eficiência na produção, mas, também, mudar padrões de consumo, otimizando o uso dos recursos naturais e minimizando a criação de rejeitos. É dentro dessa problemática que se enquadra a discussão a respeito do consumo de energia nas indústrias de calçados da cidade de Campina Grande (PB).

Com relação à utilização de energia elétrica, que é a fonte de energia utilizada na indústria de calçados, verificou-se um consumo médio mensal de $498 \mathrm{~kW} / \mathrm{h}$ nas microempresas e $2.450 \mathrm{~kW} / \mathrm{h}$ nas pequenas empresas. Em termos de comparação, tem-se que uma residência de $110 \mathrm{~m}_{2}$ com três 
moradores, possui um consumo médio mensal de $190 \mathrm{~kW} / \mathrm{h}$, representando menos da metade do consumo médio de uma microempresa.

Segundo Cohen (2005), o consumo baixo por residência, conseqüentemente, por habitante, torna a conservação de energia como variável não-prioritária na preocupação ambiental industrial. Logo, deve haver uma constante preocupação com a minimização do consumo como condição para a redução de impactos ambientais.

Quanto à geração de resíduos, o principal gerado na indústria calçadista é o resíduo sólido, sendo o couro, o sintético, a borracha, papelão e latas de cola os mais representativos. O desperdício de matéria-prima que proporciona a geração de resíduos no setor de calçados fica em torno de $8 \%$ a $10 \%$ da quantidade de matéria-prima; portanto, quanto maior a indústria, maior o volume de resíduos (FRANÇA et al, 2007). Os resíduos que mais possuem destino impróprio e prejudicial ao meio ambiente são o couro e a borracha. Todavia, um fator positivo em relação ao resíduo da indústria de calçados é que uma parte é reaproveitada.

O couro é destinado quase que totalmente para o lixão: 94\% das empresas destinam seus resíduos para o lixo e apenas $6 \%$ vendem ou os doam para serem reutilizados. Essa reutilização é feita geralmente por fabricantes de produtos pequenos feitos de couro, como chaveiros ou bijuterias. Por sua vez, a borracha também possui um destino bastante impróprio e prejudicial ao meio ambiente, pois todo o resíduo de borracha produzido nas empresas que compõem o APL também é destinado ao lixão através da coleta de lixo. De um modo geral, estes são dois materiais que possuem um período de degradação bastante elevado, onde o couro possui um período de degradação de 20 anos e a borracha, o período é indeterminado.

Com relação a variável Atendimento a legislação, verificou-se que a grande maioria das empresas do arranjo em análise (86,4\%) não possuem o licenciamento ambiental exigido pela Superintendência de Administração do Meio Ambiente - SUDEMA (FRANÇA et al, 2007).

Percebeu-se ainda o baixo interesse das empresas do setor em procurar obter a licença, sendo os principais fatores o custo e a falta de interesse do órgão supracitado em proporcionar esclarecimentos e incentivar a preocupação com as questões ambientais.

Ao analisar os Impactos Ambientais, foi identificada a necessidade em se trabalhar ferramentas de gestão ambiental que visem minimizar os impactos ambientais ocasionados pelo setor ao meio ambiente, estando essas questões presentes na pauta de incentivos dos governantes estaduais e municipais. Logo, torna-se prudente a realização de novas pesquisas referentes ao uso dos resíduos da indústria calçadista, podendo gerar na sociedade oportunidades econômicas ambientalmente corretas.

Algumas empresas já identificam direcionamentos para melhorar a vida útil do seu produto, bem como estão procurando dar encaminhamento aos resíduos que podem ser reciclados, ou 
reutilizados em processos diversos, diminuindo o impacto ambiental e gerando uma nova fonte de receita para o empreendimento. Por outro lado, não existe uma conscientização da importância da minimização de entradas e saídas de materiais para o meio ambiente, pois a preocupação das empresas é muito mais no sentido de buscar aumentar os seus lucros a partir de novas relações comercias (FURLANETTO; SANTOS, 2009).

Diante de tais considerações, pode-se perceber que as empresas do setor vêm assumindo uma postura relativamente responsável no que diz respeito à utilização de práticas de preservação ambiental, na medida em que alguns quesitos essenciais da sustentabilidade ambiental não são atendidos em conformidade com o esperado conforme mencionado anteriormente.

\subsubsection{Sustentabilidade social}

No que concerne à variável assumir responsabilidade social verifica-se a ausência de ações mais prementes relacionados a tal variável por parte das organizações que compõem o APL, o que indica que as empresas não reconhecem ainda a importância dessas ações e, principalmente, não a percebem como importante instrumento de apoio as estratégias e que podem proporcionar vantagens competitivas para as organizações que a adotam.

Sendo assim, é necessário que as empresas pertencentes ao APL em análise se conscientizem da importância das ações de responsabilidade social, e atuem investindo em financiamentos da ação social no município no qual atuam, fomentando o desenvolvimento sustentável do mesmo, preservando os seus valores e possibilitando uma melhor qualidade de vida para os seus funcionários e familiares que compõem a comunidade local.

De modo análogo à variável responsabilidade social, as organizações se portam frente à variável suporte ao crescimento da comunidade, onde estas não possuem um gerenciamento do impacto que causa na comunidade adjacente, nem apresentam relações com as organizações locais, que poderiam trazer benefícios para a comunidade gerando ações de valorização, do ambiente e da cultura local.

As empresas reconhecem a importância da liderança social e do seu papel e influência frente à sociedade, modificando assim os seus procedimentos, mas ainda não consideram de relevância a participação em projetos sociais propostos pelos governantes. Vale destacar, que o despertar das empresas para a importância da sua influencia e liderança local, ocorreu por possuírem interesses nas vantagens que podem obter ao explorarem e persuadirem algumas vezes a comunidade local, entretanto, não faz o que as cabem em contrapartida - investir na comunidade.

Quanto à variável compromisso com o desenvolvimento dos recursos humanos, constata-se

que o arranjo conta com infra-estrutura educacional com os cursos oferecidos pelo SENAI no 
CTCC. Cabe observar a contribuição do CTCC como mecanismo formal de aprendizado para o arranjo, através da formação e treinamento de mão-de-obra e também nas suas atividades de atendimento tecnológico às empresas. Sua capacitação laboratorial e de recursos humanos, incluindo os pesquisadores e professores da UFPB que atuam em parceria, consiste em forte potencial de desenvolvimento tecnológico do arranjo, apesar de ser, ainda, parcialmente utilizado pelas empresas.

Assim, ressalta-se que a grande capacitação e patrimônio do arranjo localizam-se no conhecimento tácito existente nos indivíduos e no que permite de geração de inovações e soluções específicas, seja nos equipamentos adaptados, nos insumos utilizados (como é o caso dos solados reciclados do lixo plástico), nos mecanismos específicos de gestão da produção ou mesmo nos nichos de mercado vislumbrados para atuação (LEMOS; PALHANO, 2000).

Quanto à promoção e participação em projetos de cunho social, verifica-se que as empresas do APL de Calçados de Campina Grande, ainda estão arraigadas a procedimentos burocráticos, manifestando-se apenas nas exigências legais, sem levar em conta a sua participação na formação da cidadania e o seu papel de ator social para a construção de uma sociedade mais consciente e mais transparente.

Diante das observações, identifica-se certa carência de ações sociais no APL em estudo, dado que este adota uma postura imediatista frente as novas exigências organizacionais, focando-se muito mais em aspectos que gerem retorno econômicos de curto prazo.

\section{Considerações finais}

Com base no que foi exposto por este estudo, foi possível verificar a necessidade das empresas que compõem os APLs atuarem de modo conjunto e integrado, como forma de fortalecerem-se no atual ambiente organizacional globalizado, incorporando princípios que ultrapassem o limite da esfera econômica, voltando-se para aspectos sociais e ambientais, de modo a garantir a sustentabilidade corporativa.

A sustentabilidade empresarial passa a ser um desafio para as organizações, sobretudo as de pequeno porte, uma vez que esta dependerá de sua competitividade, da sua relação com o meio ambiente, bem como de ações de responsabilidade social.

Com relação à sustentabilidade econômica, o APL calçadista de Campina Grande se destaca na região em virtude da sua forma de atuação no mercado, destacando-se com menor intensidade em nível nacional e internacional. Pode ser considerado regularmente satisfatório, na medida em que gera uma grande quantidade de emprego e renda quando comparado com demais setores, todavia prevalece ainda a informalidade e reduzidos salários. 
Quanto à sustentabilidade ambiental, não foram constatadas medidas efetivas direcionadas para a preservação ambiental, tais como programas de gerenciamento ambiental, principalmente a grande quantidade de resíduos que a indústria de calçados gera e que ainda são destinados a lixões a céu aberto. Tal situação sugere a necessidade de se trabalhar com ferramentas de gestão, criação de programas de educação e conscientização ambiental para os funcionários, bem como para a comunidade local que possibilitem a redução dos impactos negativos deste setor industrial ao meio ambiente.

No tocante às questões sociais, percebeu-se que o APL reconhece a importância da adoção de práticas que promovam o bem-estar de seus funcionários e da comunidade em geral, para tanto, tais práticas ainda são inexistente. Foi constatado a presença de centros educacionais que tem por objetivo o apoio ao crescimento e desenvolvimento do arranjo, entretanto, a maioria das empresas não mantém relações consolidadas com tais centros, o que inviabiliza a aprendizagem para inovação, restringindo o acesso a novas informações e conhecimento que contribuam com melhorias nos produtos e processos.

De modo geral, recomenda-se que o APL Calçadista de Campina Grande busque formas alternativas de fomentar sua sustentabilidade empresarial, através de práticas efetivas que integrem aspectos sociais, ambientais e econômicos para que de forma articulada e integrada promovam o tão almejado desenvolvimento.

\begin{abstract}
The article aims to describe the implementation of corporate sustainability practices of the Footwear APL from Campina Grande - PB. We used as a basis the model proposed by Coral (2002), which comprises three dimensions of sustainability: economic, social and environmental. Methodologically the research is characterized as being descriptive and conducted in the form of case study. Regarding the techniques, we used the literature review, document analysis and nonparticipant observation. The study results indicate that there is a need for companies that make up the APLs act in a joint and integrated, in order to strengthen themselves in the globalized industrial organizations, incorporating principles that go beyond the limit of the economic sphere, turning to the social and environmental, to ensure corporate sustainability.
\end{abstract}

Keywords: local cluster; social sustainability, economic sustainability, environmental sustainability.

\title{
Referências
}

ALMEIDA, J. R. de. Planejamento ambiental: caminho para a participação popular em gestão ambiental para nosso futuro comum: uma necessidade, um desafio. Rio de Janeiro: Ed. Biblioteca Estácio de Sá, p. 45-128,1999.

ALMEIDA, R. O. Ecoeficiência e as empresas do terceiro milênio. Tendência do Trabalho. set. 1998. Disponível em: <www.perspectiva.com.br/leitura/18c.htm>. Acesso em: 22 abr. 2005.

ALTENFELDER, R. Desenvolvimento sustentável. Gazeta Mercantil. 06 maio, 2004. 
ARAGÃO, P. O. R. de. Arranjos Produtivos de Couros e Calçados de Campina Grande/PB. Relatório de Pesquisa Projeto PROMOS/BID/SEBRAE. Brasília, 2006.

ASSOCIAÇÃO BRASILEIRA DAS INDÚSTRIAS DE CALÇADOS - Abicalçados. Disponível em: $<$ http://www.abicalcados.com.br $>$.

BANCO DE DESENVOLVIMENTO ECONÔMICO E SOCIAL - BNDES. Arranjos Produtivos Locais e Desenvolvimento. Rio de Janeiro, Área de Planejamento e Departamento de Produtos - DEPRO, 2004.

BOISIER, S. Sociedad del Conocimiento, conocimiento social y gestión territorial. Interações, Campo Grande, v.2,n.3, p.09-28,mayo 2001.

BRUNDTLAND - REPORT. World Comission on Environment and Development: our common future. Oxford and New York, 1987.

BUARQUE, S. C. Metodologia de planejamento do desenvolvimento local e municipal sustentável. 2.ed. Recife: IICA, 1999.

CARVALHO, O.; VIANA, O. Ecodesenvolvimento e equilíbrio ecológico: algumas considerações sobre o Estado do Ceará. Revista Econômica do Nordeste. Fortaleza, v. 29, n. 2, abr./jun. 1998.

CASAROTTO FILHO, N.; PIRES, L.M. Redes de pequenas empresas e desenvolvimento local: estratégias para a competitividade global com base na experiência italiana. São Paulo: Atlas, 1999.

CASSIOLATO,J; SZAPIRO. Aglomerações e sistemas produtivos e inovativos locais: em busca de uma caracterização voltada ao caso brasileiro. Rio de Janeiro: IE - UFRJ. (Texto para Discussão, Projeto Aglomerações E Sistemas Produtivos Locais Em Busca De Uma Caracterização Voltada Ao Caso Brasileiro), 2002.

CAVALCANTI, C. Política de governo para o desenvolvimento sustentável: uma introdução ao tema e a esta obra coletiva. In: CAVALCANTI, Clóvis (org.). Meio ambiente desenvolvimento sustentável e políticas públicas. São Paulo: Cortez: Recife: Fundação Joaquim Nabuco, 2001.

COHEN, C. Padrões de consumo, energia e meio ambiente. Niterói: Universidade Federal Fluminense, 2005. (Textos para discussão - Economia, 11).

CORAL, E. Modelo de planejamento estratégico para a sustentabilidade empresarial. 2002. 282f. Tese (Doutorado em Engenharia da Produção). Universidade Federal de Santa Catarina, Florianópolis - SC, 2002.

DOWBOR, L. Gestão Social e transformação da sociedade. In: DOWBOR, L.; KILSZTAJN, S. (org.). Economia Social no Brasil. São Paulo: Editora SENAC, 2001.

FISCHER, R. M. A Responsabilidade pelo Desenvolvimento. Texto de Apoio à Prova de Erudição do Concurso para Provimento do Cargo de Professor Titular do Departamento de Administração da FEA/USP. São Paulo: Julho 2003.

FRANÇA, P. X. N.; LEITE, V. D.; PRASAD, S. Análise dos Impactos Socioambientais das Micro e Pequenas Indústrias de Calçados Instaladas na Cidade de Campina Grande. Revista Econômica do Nordeste, Fortaleza, v. 38, $\mathrm{n}^{\circ}$ 3, jul-set. 2007.

FURlanetTO, E. L.; SIlva, R. J. A.; AlBUQUERQUE NETO, H. C. Avaliação do nível de Capacidade Tecnológica das Empresas do APL de Calçados de Campina Grande e Formulação de um Plano Estratégico de Inovação. In: IV Congresso de Iniciação Científica da Universidade Federal de Campina Grande, 2007.

FURLANETTO, E. L.; SANTOS, S. F. M. Revista INGEPRO on line Disponível em: http://www.ingepro.com.br/index.php/ingepro/article/view/70. Acessado em: 10/Junho/2009. Vol. 1, n. 4, 2009.

LEMos, C.; PAlhano, A. Arranjo Produtivo Coureiro-Calçadista de Campina Grande/PB. Nota técnica 20/ UFRJ. Rio de Janeiro: 2000.

MAIMON, D. Passaporte verde: gestão ambiental e competitividade. Rio de Janeiro: Qualitymark, 1996.

MARSHALL, A. Princípios de economia. São Paulo: Nova cultural, 1985. 
MAXIMIANO, A. C. A. Teoria geral da administração: da escola científica à competitividade globalizada. São Paulo: Atlas, 2000.

MELLO NETO, F. P.; FROES, C. Responsabilidade social e cidadania empresarial: a administração do terceiro setor. 2. ed. Rio de Janeiro: Qualitymark, 1999.

MUELLER, C. C. Os economistas e as relações entre o sistema económico e o meio ambiente. Brasília: Editora Universidade de Brasília: Finatec, 2007.

PUGA, F. P. Alternativas de apoio a MPMES localizadas em arranjos produtivos locais. [S.L.]: BNDES, 2003. (Texto para discussão, n. 99). Disponível em: $<$ http://redeincubar.anprotec.org.br:8280/portal/baixaFcdAnexo.do?id=6 $>$. Acesso em: 12 Nov. 2004.

RUTHES, S.; NASCIMENTO, D. E. Desenvolvimento Sustentável e os Arranjos Produtivos Locais. In: Anais do IX Simpósio de Administração da Produção, Logística e Operações Internacionais-SIMPOI. São Paulo-SP, 29-31agosto, 2006.

SERVIÇO BRASILEIRO DE APOIO ÀS MICROS E PEQUENAS EMPRESAS. Boletim estatístico de micro e pequenas empresas. Observatório SEBRAE. Disponível

$\mathrm{em}:<$ http://www.SEBRAEmg.com.br/Geral/visualizadorConteudo.aspx?Cod areaconteudo+520>. Acesso em: 2 Set. 2005 .

SMITH, C. The New Corporate Philanthropy. Harvard Business Review, May-June 1994.

YOUNG, C.E.F.; STEFFEN, P.G. Instrumentos econômicos são uma mão na roda. Adiante: Inovação para Sustentabilidade. São Paulo: FGV-CES, n. 3, mar. 2006.

\section{Dados dos autores:}

Nome completo: Raquel Andrade Barros.

Filiação institucional: Universidade Federal da Paraíba - UFPB

Departamento: Programa de Pós-Graduação em Engenharia de Produção - PPGEP

Função ou cargo ocupado: Mestranda

Endereço completo para correspondência: Rua Aprígio Ferreira Leite, 36, Catolé. CEP: 58410-515.

Campina Grande - PB - Brasil.

Telefones para contato: (83) 8854-2867

e-mail: barrosrab@gmail.com

Nome completo: Elisabeth de Oliveira Andrade.

Filiação institucional: Universidade Federal da Paraíba - UFPB

Departamento: Programa de Pós-Graduação em Engenharia de Produção - PPGEP

Função ou cargo ocupado: Mestranda

Endereço completo para correspondência: Rua Dom Pedro II, 479, Prata. CEP:58428-850. Campina Grande - PB, Brasil.

Telefones para contato: (83) 8886-8943

e-mail: bethoandrade@gmail.com 
Nome completo: Ana Cecília Feitosa de Vasconcelos

Filiação Institucional: Universidade Federal da Paraíba - UFPB

Departamento: Programa de Pós-Graduação em Engenharia de Produção - PPGEP

Função ou cargo ocupado: Mestranda

Endereço completo para correspondência: Rua Frei Martinho, 113, Conceição. CEP: 58102-433.

Campina Grande - PB - Brasil.

Telefone para contato: (83)8825-4990

e-mail: acvasconcelos@gmail.com.br

Nome Completo: Gesinaldo Ataíde Cândido

Filiação Institucional: Universidade Federal de Campina Grande - UFCG

Departamento: Administração e Contabilidade

Função ou cargo ocupado: Professor titular em Administração Geral

Endereço Completo: Rua Esperidião Rosas, 235/703, Expedicionários, CEP: 58041-070, João

Pessoa - PB - Brasil.

Telefone para contato: (83) 3242-1155

e-mail: gacandido@uol.com.br 